\title{
The Close-Call in Microbiology Labs - Understanding Microbes
}

\author{
Seema G. Thomas, Maryah A. Glover, Anutthaman Parthasarathy, and André \\ O. Hudson
}

Thomas H. Gosnell School of Life Sciences, Rochester Institute of Technology, 84 Lomb Memorial Dr, Rochester NY 14623 USA

(sgtsbi@rit.edu; mag3461@rit.edu; axpsbi@rit.edu; aohsbi@rit.edu)

For a sophomore student, new to microbiology lab, most of the microbial colonies look alike - kind of a toddler's view on a dog or a cat; both have 4 legs and a tail, and now what?! The students level of confidence increases within a few weeks as they learn to identify the morphology - the form, the elevation, the margin and the list goes on, followed by the same protocol of testing antimicrobial susceptibility using antibiotic discs and measuring the zone of inhibition with a ruler. My question: Why not include a more relevant approach to learn techniques which demonstrates that the same microbe responds differently based on the form in which they exist; planktonic or biofilm - either relating to clinical biomaterials like stents in human body and its antibiotic treatments or biofilms in Lake Ontario water supply channels and chlorine/ disinfectant treatment as related to the environment.This will enhance their learning on current real world applications, as in medical, scientific or pharmaceutical settings. This paper discusses a study based on determining the Minimum Inhibitory Concentration, Minimum Biofilm Eradication Concentration using the antibiotics neomycin sulfate and co-trimoxazole on the opportunistic pathogens Citrobacter freundii and Aeromonas hydrophila as model organisms, using cost effective 96 wells plates. The results showed a trend indicating higher antibiotic concentrations and increased biofilm elimination, concluding the need of a higher concentration for biofilm eradication rather than the bare minimum concentration of $1 \mathrm{mg}$ $\mathrm{mL}^{-1}$ antibiotics used in the study.

Keywords: Biofilm, planktonic antibiotic susceptibility, Minimum Inhibitory Concentration (MIC), Minimum Biofilm Eradication Concentration (MBEC)

\section{Introduction}

Recognized as the predominant form of bacteria in nature, the biofilm is a surface adherent, irregularly structured community of microorganisms encased in an extracellular polymeric matrix (Lawrence et al. 1991), which are controlled by various genetic and environmental factors compared to its distinctive counterpart, the free-floating planktonic forms. This section of the current study was focused on enhancing the course based undergrad learning experience similar to CURE (Course Based Undergraduate Research Experiences). Biofilms present with a well-known 10-100-fold increase in tolerance to antibiotics relative to the planktonic form (De Beer et al.1994; Donlan and Costerton 2002; Olson et al. 2002; Costerton et al. 1999; Keren et al. 2004). To augment the learning concept, why not include a more relevantapproach to learn recent techniques which demonstrates that the same microbe responds differently based on the form in which they exist; planktonic or biofilm - either relating to clinical biomaterials like stents in human body and its antibiotic treatments or biofilms in Lake Ontario water supply channels and chlorine/disinfectant treatment as related to the environment. Over more, the minimal inhibitory concentrations (MIC) of antibiotics are routinely determined using planktonic bacteria and do not match the concentrations that are required to prevent, inhibit, diminish or eradicate biofilms (Macia et al. 2014). This will enhance their learning on current real-world applications, as in medical, scientific or pharmaceutical settings. This paper discusses a study based on 
determining the Minimum Inhibitory Concentration (MIC), Minimum Biocidal Concentration (MBC) and Minimum BiofilmEradication Concentration (MBEC) using two antibiotics, Neomycin sulfateCotrimoxazole and (Sulfamethoxazole and Trimethoprim) on Citrobacterreundii (CF) and Aeromonas hydrophila (AH) as model organisms, using cost effective 96 wells plates. 


\section{Student Outline}

\section{Objectives}

- Compare antibiotic susceptibility between biofilms and planktonic forms of bacteria

- Determine the Minimum Inhibitory Concentration (MIC), Minimum Biocidal Concentration (MBC) and

- Minimum Biofilm Eradication Concentration (MBEC) using two antibiotics, Neomycin sulfate Cotrimoxazole (Sulfamethoxazole and Trimethoprim) on Citrobacter freundii (CF) and Aeromonas hydrophila $(\mathrm{AH})$

\section{Introduction}

This study will attempt to shed light on the impact of biofilms on IMD's (Indwelling Medical Devices), environmental water systems and other industries and the challenges faced in the eradication of biofilms. The investigation focused on the biofilm eradication concept using the cost-effective 96 well plate MBEC assay. The high- throughput method of biofilm MIC, MBC and MBEC determination using Neomycin Sulfate Co-trimoxazole (SulmethoxazoleTrimethoprim) at the concentration of $1 \mathrm{mg} / \mathrm{ml}$ on the two gram negative bacteria, A. hydrophila and C. freundii allows us to determine their biofilm formation and eradication rates at the specified growth conditions.

\section{Methods and Data Collection}

\section{Bacterial Strains and the MBEC Assay Device}

Second sub-cultures of two gram negative bacteria viz., Citrobacter freundii and Aeromonas hydrophila grown in TSB media were adjusted to a cell density of $10^{-6} \mathrm{cfu} / \mathrm{ml}$ and were used in the high throughput screening MBEC assay to determine the efficacy of antimicrobials against biofilm and its Minimum Inhibitory Concentration in a short period of time. The device from Innovotech, the MBEC assay inoculator with a corresponding trough base and 96 pegs lid on which the biofilms establish were used in the current study (Fig.1). The materials needed for this study are presented in a flow chart (Fig. 2).

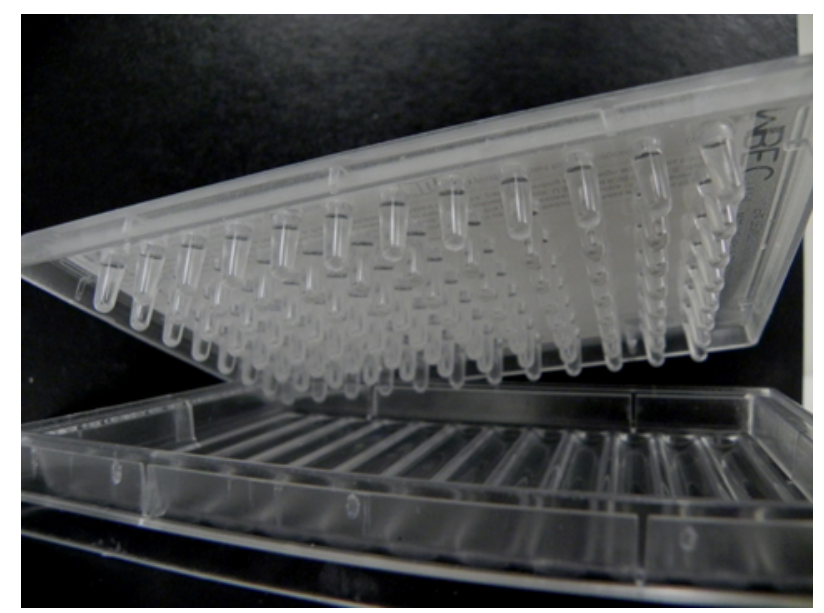

Figure 1. MBEC assay biofilm inoculator trough with 96 peg lid from Innovotech.

\section{Antibiotics}

Neomycin sulfate and co-trimoxazole (trimethoprim/sulfamethoxazole), serially diluted with the highest concentration at $1 \mathrm{mg} / \mathrm{ml}$ each were used as antibiotics. The MBEC, MBC and MIC were analyzed following the standard protocol as per Innovotech's MBEC assay.

The MBEC assay workflow is presented in Fig. 3. The protocol was minimally modified for this assay. The antibiotic concentrations used in each of the 8 rows of the 96 well plate are presented in Table 1. 


\section{Biofilm Formation and Biofilm Growth Check}

Cultures of both $A$. hydrophila and $C$. freundii at the above-mentioned cell density were added to two individual trough bases and incubated at $37^{\circ} \mathrm{C}$ on a rocking platform. The established biofilm peg lids were transferred to a series of 96 well plate for testing the MBEC, MBC and MIC, alongside sterility control wells.

A serial dilution of $10^{-0}$ to $10^{-7}$ was prepared by transferring $20 \mathrm{uL}$ to each of the 8 rows of the 96 well plate. $20 \mathrm{uL}$ were removed from each well and spot plated onto the TSA plates. The 96 well plate was then incubated on a rotary shaker at $37^{\circ} \mathrm{C}$ for 16 hours. Biofilm growth check was performed and immediately following incubation, specified pegs were removed from the lids using flame-sterilized pliers and each were placed in a new 96 well plated with recovery media. The plate was sonicated for 30 minutes to recover the biomass. The cell density was confirmed by serially diluting and spot plating.

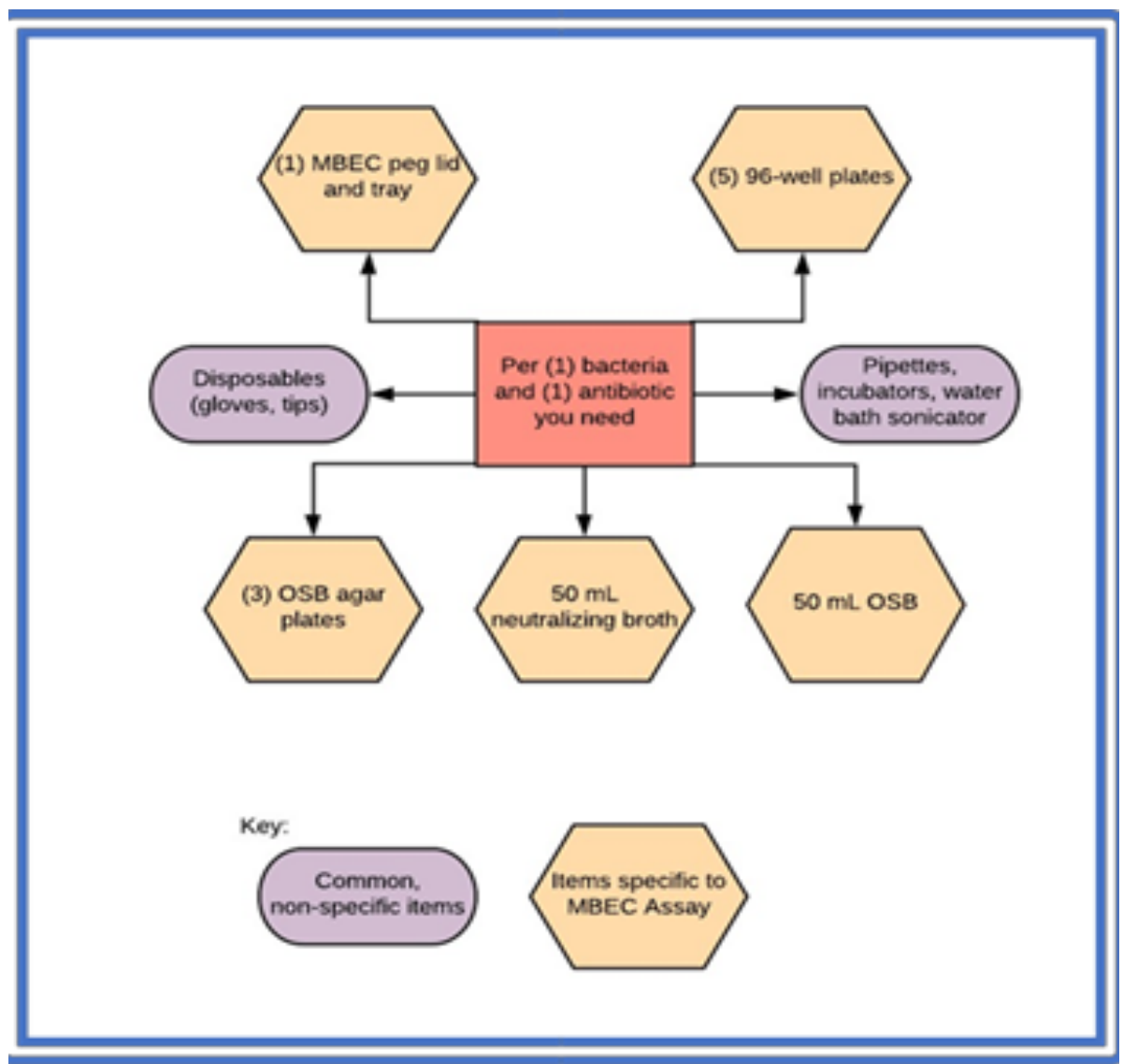

Figure 2. Schematic representation of the materials needed for the cost effective MBEC assay. 


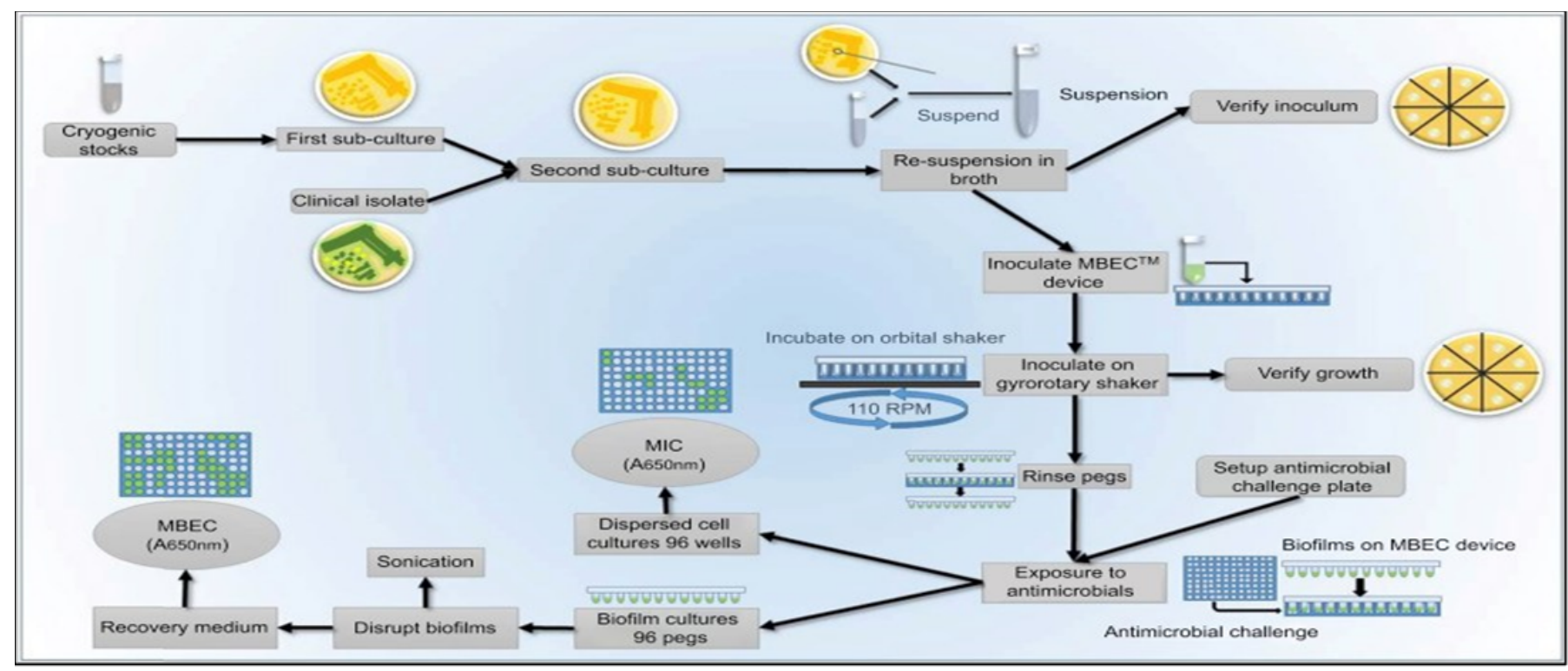

Figure 3. Schematic representation of the high thru' put In Vitro antimicrobial testing model to evaluate efficacy of Cotrimoxazole (Sulfmethoxazole and Trimethoprim) and Neomycin Sulfate on the MIC, MBC and MBEC on C. freundii and A. hydrophila (MBEC 2019). (Protocol modified minimally from the Innovotech MBEC assay).

Table 1. Levels of antibiotic concentrations used in each row of the 96 well plate in the determination of MIC, MBC and MBEC on A. hydrophila and C. freundii.

\begin{tabular}{|l|l|l|}
\hline $\begin{array}{l}\text { Rows in } \\
\text { 96 well } \\
\text { plate }\end{array}$ & $\begin{array}{l}\text { Concentration } \\
\text { (ug/mL) }\end{array}$ & Percentage \\
\hline A & 1000.0 & 100.00 \\
B & 500.0 & 50.00 \\
C & 250.0 & 25.00 \\
D & 125.0 & 12.50 \\
E & 62.5 & 6.25 \\
F & 31.3 & 3.13 \\
G & 15.6 & 1.56 \\
H & 7.8 & 0.78 \\
\hline
\end{tabular}

\section{The Challenge Plate}

The challenge plate was prepared by diluting a $1 \mathrm{mg} / \mathrm{ml}$ stock solution of Neomycin sulfate and co-trimoxazole in each row. TSB, sterile neutralizer and water were added to 3 specific wells, which are sterility, neutralizer and neutralizer effective control plate. The challenge plate was freshly prepared and used within 30 minutes. 


\section{The Rinse Plate}

The rinse plate was prepared by adding $180 \mathrm{uL}$ of $0.9 \%$ sterile saline to a new 96 well plate. The peg lid was rinsed by setting the lid into rinse plate for 10 seconds. The peg lid was transferred to the challenge plate and incubated as per protocol.

\section{The Recovery Plate}

The recovery plate was prepared by adding $200 \mathrm{uL}$ of neutralizer media to a new plate and after appropriate time the peg lid was transferred to the recovery plate. The device was again sonicated to remove the attached biofilm.

\section{MBEC Determination}

$100 \mathrm{uL}$ of sterile media was added to each well of recovery plate and incubated at $37^{\circ} \mathrm{C}$ for 24 hours to determine the MBEC via a microtiter plate reader at $650 \mathrm{~nm}$. The MBEC value is the minimum concentration of antibiotic that inhibits growth of biofilm as indicated by the control wells with no turbidity.

\section{Scanning Electron Microscopy Analysis}

The A. hydrophila and C. freundii biofilms covered pegs treated with co-trimoxazole and neomycin were gently rinsed with phosphate buffer and $2 \%$ glutaraldehyde and various grades of ethanol ranging from $50-100 \%$. The fixed samples were then visualized for colonization via $5 \mathrm{kV}$ voltage scanning electron microscope.

\section{$\underline{\text { Statistical Analysis }}$}

The results were statistically analyzed using ANOVA with with $\alpha=0.05$ and Fishers $95 \%$ confidence interval. 


\section{Notes for the Instructor}

Results are summarized in Table 2.

Table 2. Overall results of the MIC, MBC and MBEC assays to evaluate the efficacy of Co-trimoxazole (C) and Neomycin Sulfate $(\mathrm{N})$ on A. hydrophila $(\mathrm{AH})$ C.freundii (CF).

\begin{tabular}{|c|c|c|c|}
\hline Assay & Antibiotic (ug/ml) & $\begin{array}{l}\text { A. } \\
\text { hydrophila }\end{array}$ & $\begin{array}{l}\text { C. } \\
\text { freundii }\end{array}$ \\
\hline \multirow[t]{2}{*}{$\begin{array}{l}\text { MIC } \\
\mathrm{ug} / \mathrm{ml}\end{array}$} & Cotrimoxazoleoxazole & $\begin{array}{l}1000 \\
\text { and } 500 \\
\mu \mathrm{g} / \mathrm{mL}\end{array}$ & $\begin{array}{l}15.6 \text { and } \\
7.8 \\
\mu \mathrm{g} / \mathrm{mL}\end{array}$ \\
\hline & Neomycin & $\begin{array}{l}62.5 \text { and } \\
32.3 \\
\mu \mathrm{g} / \mathrm{mL}\end{array}$ & $\begin{array}{l}31.3 \text { and } \\
7.8 \\
\mu \mathrm{g} / \mathrm{mL}\end{array}$ \\
\hline \multirow[t]{2}{*}{$\begin{array}{l}\mathrm{MBC} \\
\mathrm{ug} / \mathrm{ml}\end{array}$} & Cotrimoxazoleoxazole & $\begin{array}{l}125 \text { and } \\
62.5 \\
\mu \mathrm{g} / \mathrm{mL}\end{array}$ & $\begin{array}{l}31.3 \text { and } \\
7.8 \\
\mu \mathrm{g} / \mathrm{mL}\end{array}$ \\
\hline & Neomycin & $\begin{array}{l}125 \text { and } \\
62.5 \\
\mu \mathrm{g} / \mathrm{mL}\end{array}$ & $\begin{array}{l}62.5 \text { and } \\
31.3 \\
\mu \mathrm{g} / \mathrm{mL}\end{array}$ \\
\hline
\end{tabular}

The MIC of A. hydrophila when challenged with the antibiotic co-trimoxazole was found to be between 1000 and $500 \mathrm{ug} / \mathrm{mL}$; whereas the MIC with neomycin sulfate for this same bacterium was found to be between 62.5 and $32.3 \mathrm{ug} / \mathrm{mL}(\mathrm{P}<0.05)$. (Table 1). An exact numerical value could not be determined due to the nature of the protocol as concentrations decreased per row by a factor of 2. Values shown in MIC range were determined as the lowest concentration of the antibiotic where microbial growth was inhibited. The rest of the values for MIC and MBC are presented in table 2 and shows a significant difference between antibiotic concentration and biofilms $(\mathrm{P}<0.05)$ for both the organisms and the 2 antibiotics. In Aeromonas, acquired resistance increases the level of antibiotic resistance in both environmental and clinical strains (Esteve et al. 2015).

MBEC on the other hand, being the Biofilm Eradication Concentration, for both $\mathrm{AH}$ with cotrimoxazole and neomycin (Fig. 4 \& 5) and CF with cotrimoxazole and neomycin (Fig. $6 \&$ 7) showed that the concentration of the tested antibiotics at the range of 1000 to $7.8 \mathrm{ug} / \mathrm{mL}$, were able to eradicate biofilm formation to a certain extent but did not exhibit a total eradication, which could be due to the highest concentration being as low as
$1 \mathrm{mg} \mathrm{mL}-1$. Studies have shown that biofilms may have greater than a one hundred-fold increase in tolerance to antibiotics when compared to the same bacteria in a planktonic state (ASTM; Ceri et al.1999.) This is thought to be due to the physiological alteration of a microorganism upon attachment to a surface, as well as to cell specialization that may occur within biofilms.

Biofilms are much efficient to produce antibiotic defense than their planktonic forms (DeBeer et al. 1994). However, a trend indicating higher antibiotic concentrations and increased biofilm elimination was observed, concluding the need of a higher concentration of antibiotics for total biofilm eradication.

The scanning electron microscope revealed lesser number of cells in higher concentration of antibiotics and vice versa with lower concentration of antibiotics (Figs. $8,9,10$, and 11). SEM has the level of magnification and resolution necessary to enable the observation of the overall shape of microorganisms composing the biofilm, as well as their spatial organization. This type of spatial analysis provided by SEM makes it an interesting method to assess the biofilm growth on mixed surfaces (in which there is a junction between two materials), unlike the traditional methods that provide a bulk quantification.

Citrobacter freundii (Fig. 11) revealed morphological changes under the influence of co-trimoxazole; especially at lower concentrations where, the biofilm formation can be visualized with colonies towering over the other. Along with the morphological changes of the cells, the SEM based analysis also revealed structurally modified cellular products surrounding the biofilm clusters (Astan et al. 2013).

\section{Conclusion}

In the current study, despite utilizing lower concentrations of antibiotics, the data on MBEC determination of the two antibiotics on the opportunistic pathogens indicated a partial eradication of biofilm based on both the antibiotics. It can be concluded that this MBEC assay is a cost effective method that can be adopted by laboratories with ease to impart concept based hands on activity to learn the efficacy of an array of antibiotics, disinfectants and biocides with varying concentrations on biofilm eradication within a minimal time period. The results showed a trend with higher antibiotic concentrations and increased biofilm elimination, which concludes the need of a higher concentration of antibiotics for biofilm eradication, corresponding to the distinctive physiological states of the organism as in biofilms. 


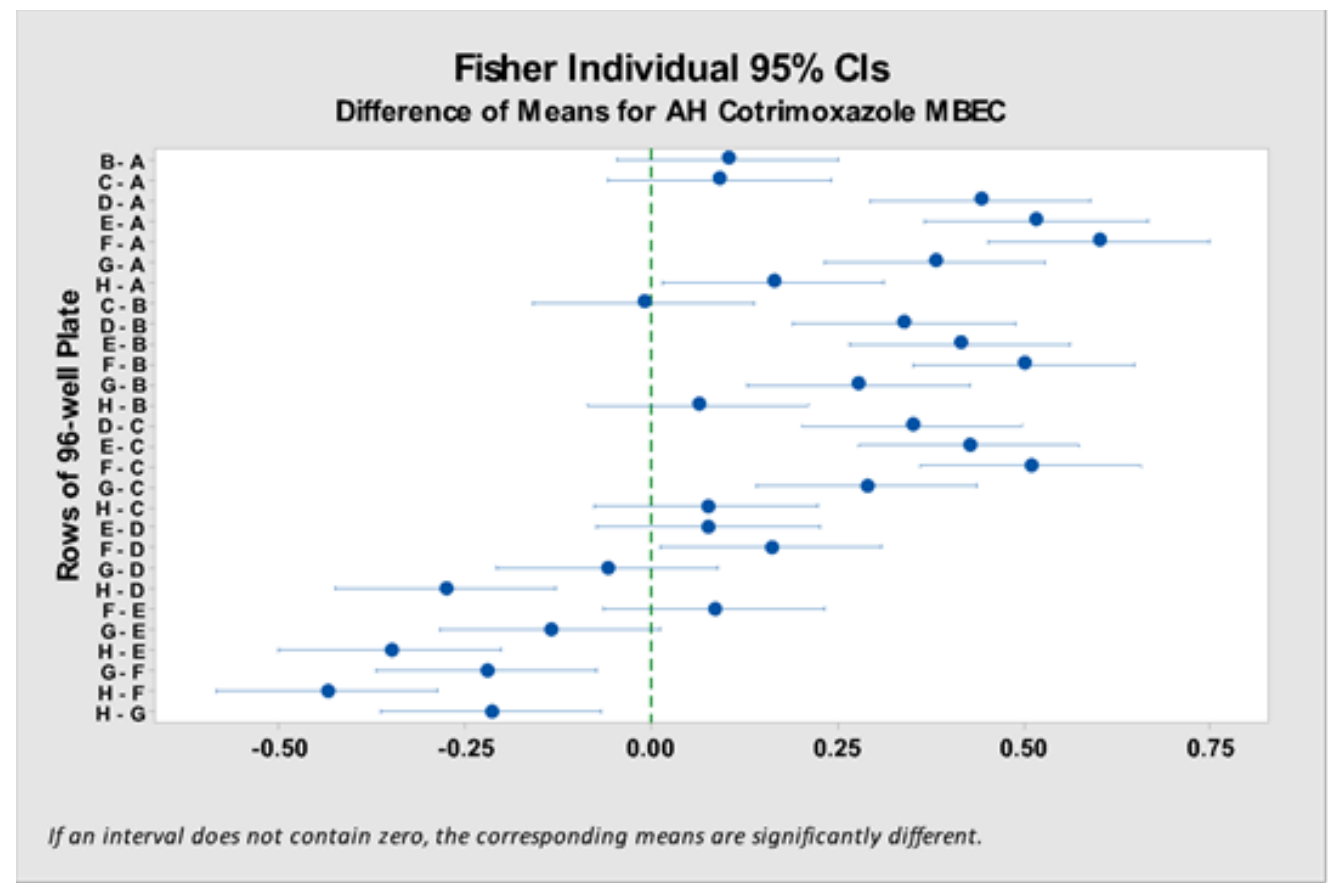

Significant difference.

Figure 4. Fisher individual confidence for AH Neutralizer plate with co-trimoxazole MBEC assay.

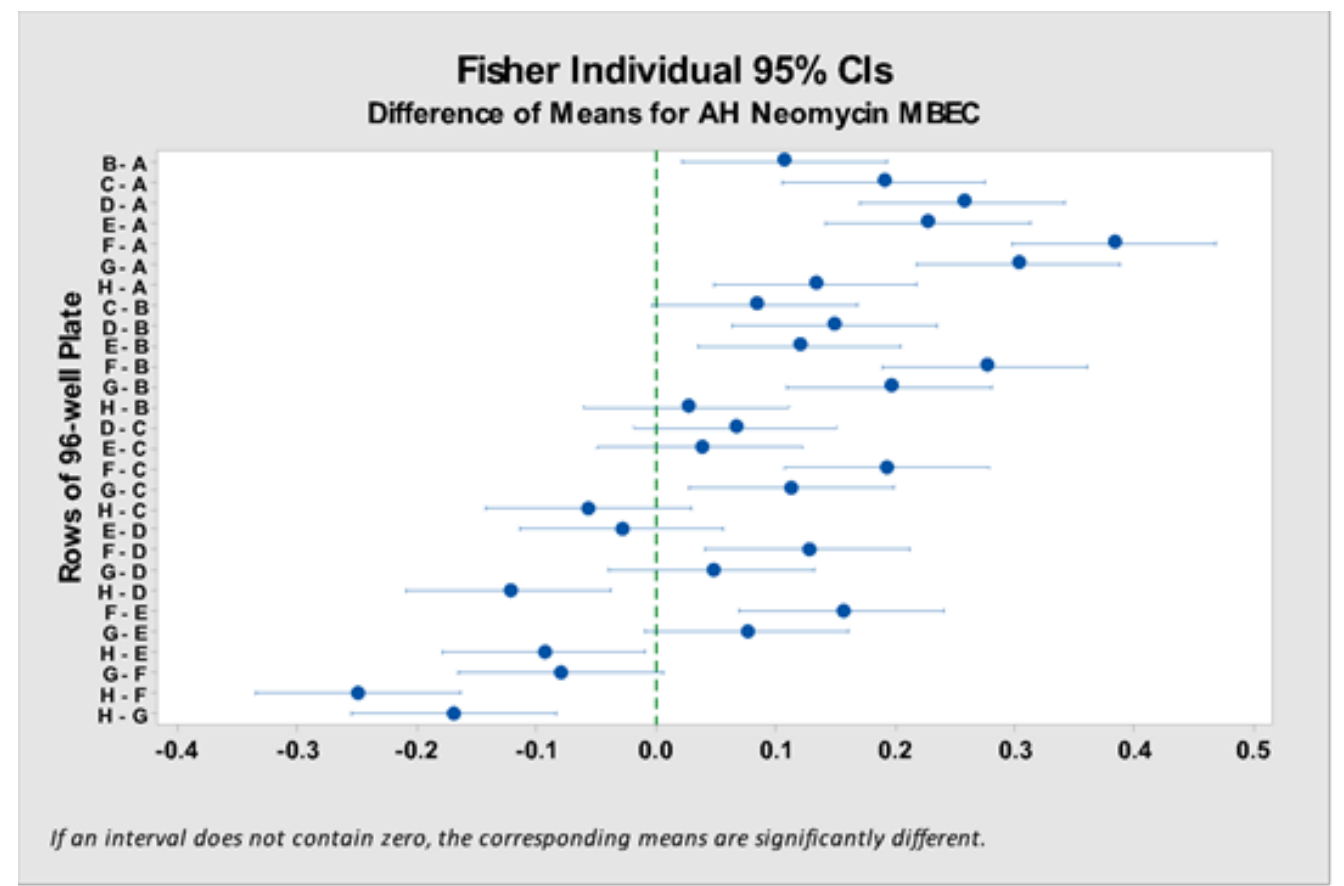

Figure 5. Fisher individual confidence for AH Neutralizer plate with neomycin. Moderate trend. 


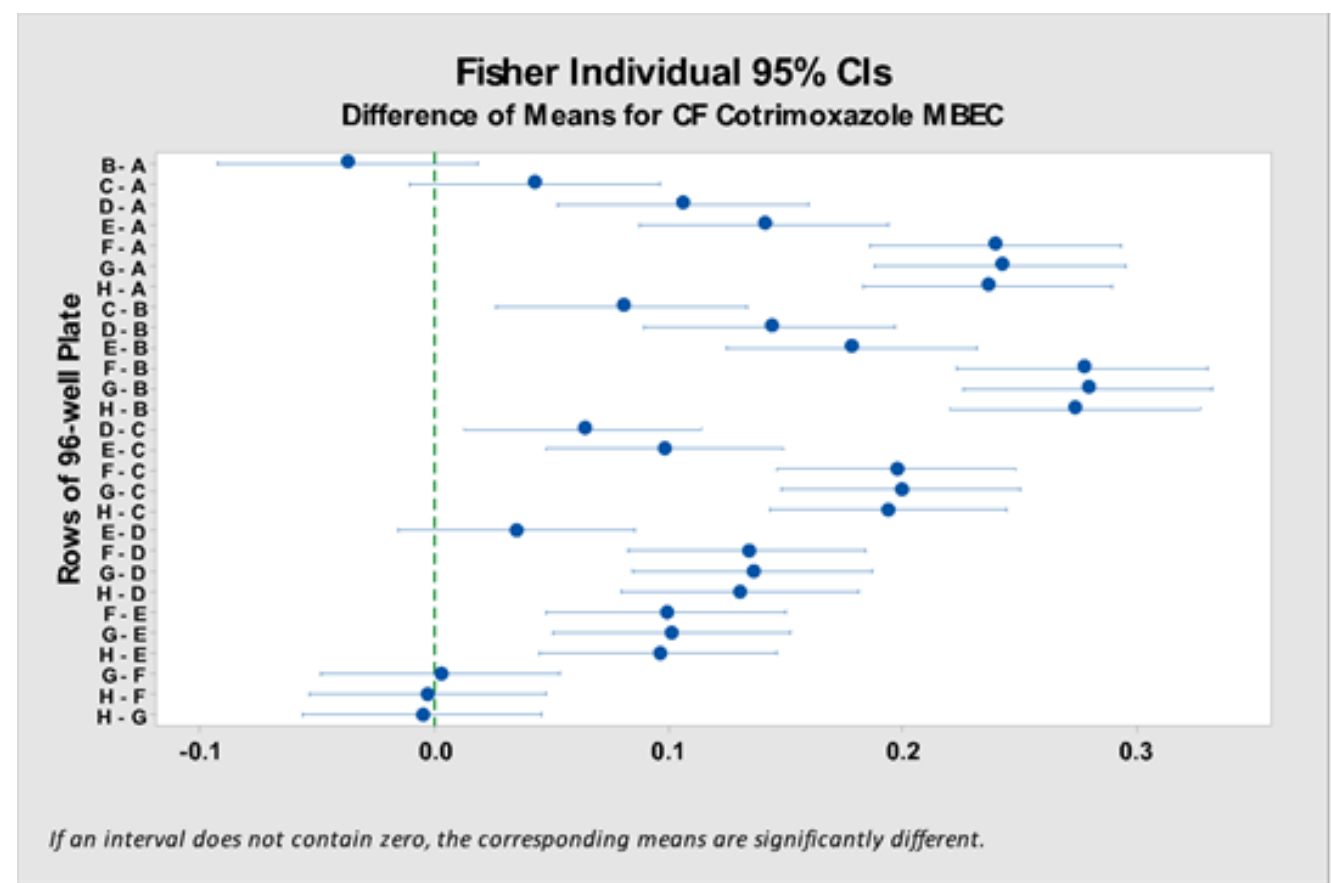

Figure 6. Absorbance readings at $590 \mathrm{~nm}$ for CF Neutralizer MBEC plate with co-trimoxazole.

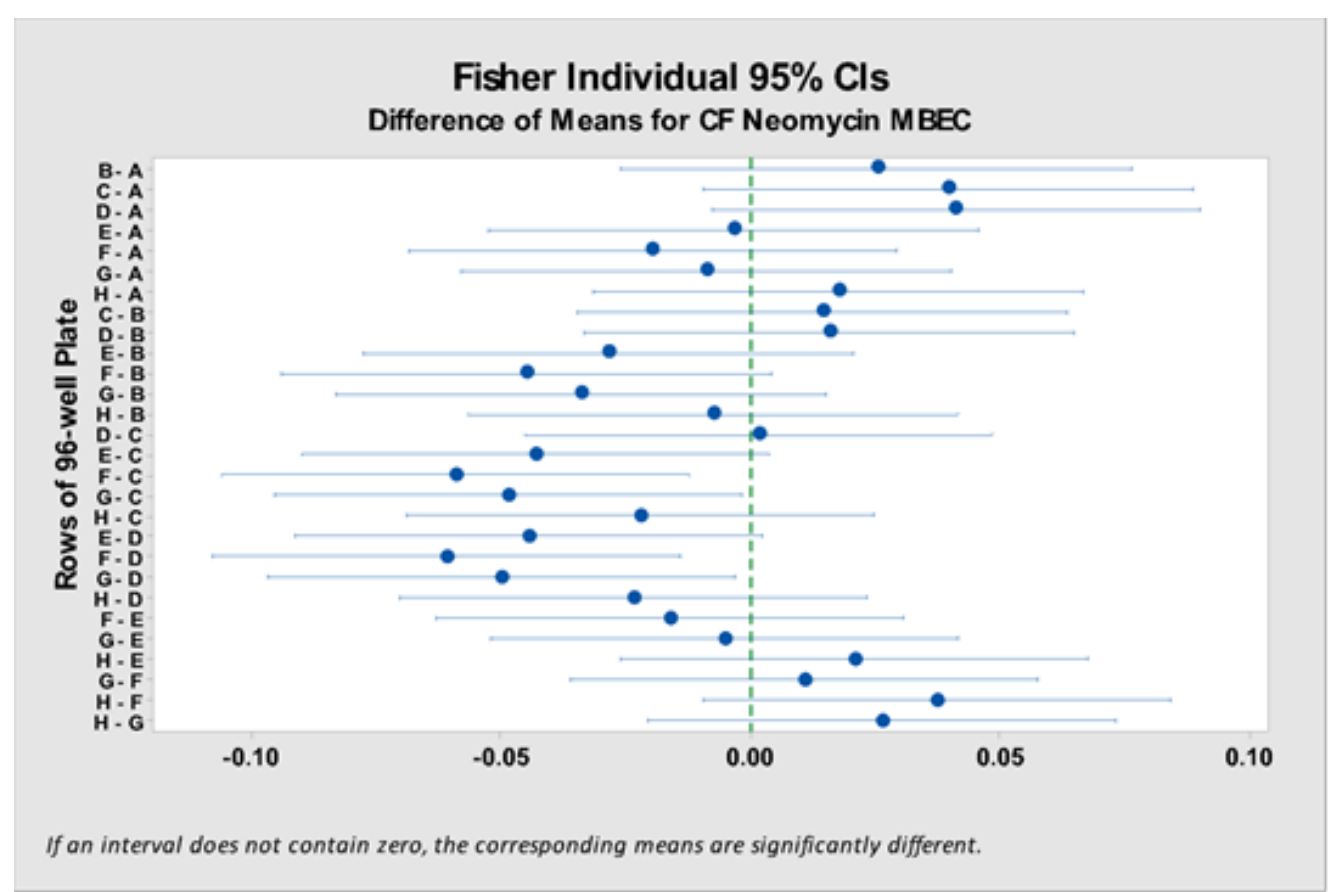

Figure 7. Fisher individual confidence for CF Neutralizer with MBEC plate with neomycin. 

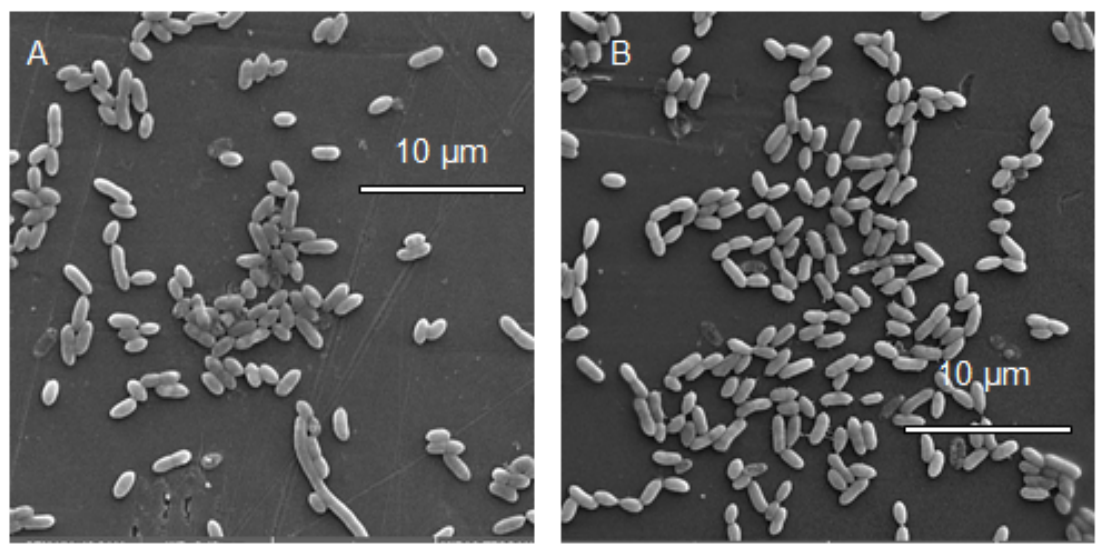

Figure 8. Scanning electron micrographs of $\mathrm{AH}$ biofilm inoculation pegs at $\mathrm{A}$ ) highest and $\mathrm{B}$ ) lowest concentrations of the antibiotic neomycin sulfate. The resolutions are 6.47 and $6.54 \mathrm{kx}$, respectively.
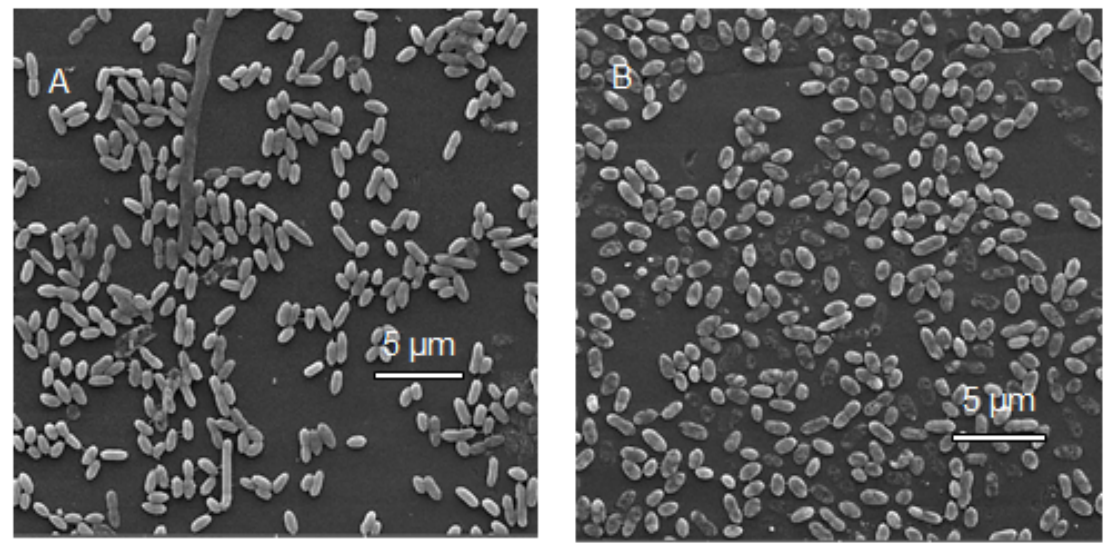

Figure 9. Scanning electron micrographs of $\mathrm{AH}$ biofilm inoculation pegs at highest (A) and lowest (B) concentrations of the antibiotic co-trimoxazole. The resolutions are 7.05 and $7.07 \mathrm{kx}$, respectively. 

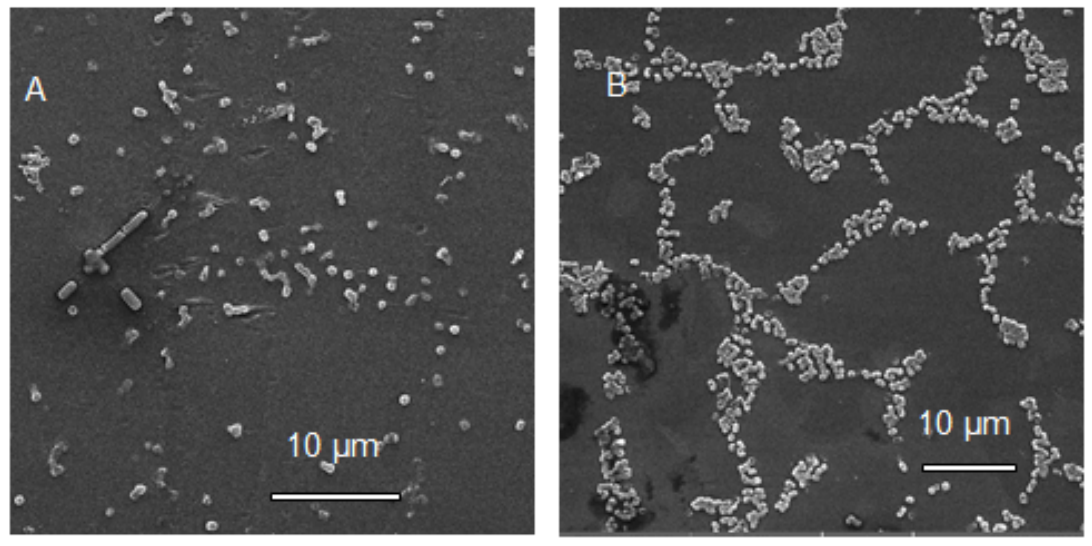

Figure 10. Scanning electron micrographs of $\mathrm{CF}$ biofilm inoculation pegs at highest (A) and lowest (B) concentrations of the antibiotic neomycin sulfate. The resolutions are 4.88 and $3.60 \mathrm{kx}$ respectively.
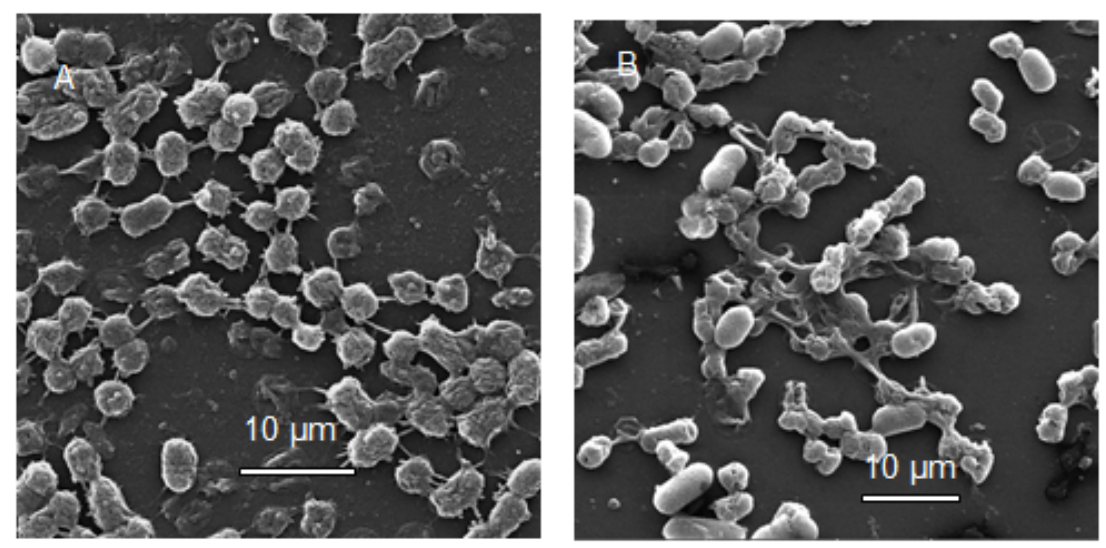

Figure 11. Scanning electron micrographs of $\mathrm{CF}$ biofilm inoculation pegs a $t$ highest $(A)$ and lowest $(B)$ concentrations of the antibiotic co-trimoxazole. The resolutions are 21.3 and $18.7 \mathrm{kx}$ respectively. 


\section{Cited References}

ASTM Standard E2799. Standard Method for

Testing Disinfectant Efficacy against Pseudomonas aeruginosa Biofilm using the MBEC Assay.

Atshan SS, Shamsudin MN, Karunanidhi A, van Belkum A, Lung LTT, Sekawi Z, Hamat RA. 2013. Quantitative PCR analysis of genes expressed during biofilm development of methicillin resistant Staphylococcus aureus (MRSA). Infection, Genetics and Evolution: Journal of Molecular Epidemiology and Evolutionary Genetics in Infectious Diseases, 18: 106-112. https://doi.org/10.1016/j.meegid.2013.05.002

Ceri H, Olson ME, Stremick C, Read RR, Morck DW, Buret AG. 1999. The Calgary Biofilm Device: New technology for rapid determination of antibiotic susceptibilities in bacterial biofilms. Journal of Clinical Microbiology 37: 1771-1776.

Costerton JW, Stewart PS, Greenberg EP. 1999.

Bacterial biofilms: a common cause of persistent infections. Science 284: 1318-1322.

DeBeer D, Stoodley P, Roe F, Lewandowski Z. 1994. Effects of biofilm structure on oxygen distribution and mass transport. Biotechnol. Bioeng. 43:1131-1138.
Donlan RM, Costerton JW. 2002. Biofilms:survival mechanisms of clinically relevant microorganisms. Clin. Micro- biol. Rev. 15: 167-193.

Keren I, Kaldalu N, Spoering A, Lewis K. 2004. Pesister cells and tolerance to antimicrobials. FEMS Microbiol. Lett. 230, 13-18.

Lawrence JR, Korber DR, Hoyle BD, Costerton JW, Caldwell DE. 1991. Optical sectioning of microbial biofilms. J. Bacteriol. 173: 6558-6567.

Esteve C, Alcaide E, Giménez MJ. 2015. Multidrug-resistant (MDR) Aeromonas recovered from the metropolitan area of Valencia (Spain): diseases spectrum and prevalence in the environment. Eur. J. Clin. Microbiol. Infect. Dis. 34, 137-145. 10.1007/ s10096-014-2210-z

Macia MD, Rojo-Molinero E, Oliver A. 2014.

Antimicrobial susceptibility testing in biofilmgrowing bacteria. Clin Microbiol Infect. 20(10):981-90.

MBEC Assay, https://www.innovotech.ca/wp-content/ uploads/2019/02/MBECProcedu ral-Manualv2.0.pdf

Olson ME, Ceri H, Morck DW, Buret AG, Read, RR. 2002

Biofilm bacteria: formation and comparative susceptibility to antibiotics. Can. J. Vet. Res. 66: 86-92. 


\section{Mission, Review Process \& Disclaimer}

The Association for Biology Laboratory Education (ABLE) was founded in 1979 to promote information exchange among university and college educators actively concerned with teaching biology in a laboratory setting. The focus of ABLE is to improve the undergraduate biology laboratory experience by promoting the development and dissemination of interesting, innovative, and reliable laboratory exercises. For more information about ABLE, please visit http://www.ableweb.org/。

Advances in Biology Laboratory Education is the peer-reviewed publication of the conference of the Association for Biology Laboratory Education. Published articles and extended abstracts are evaluated and selected by a committee prior to presentation at the conference, peer-reviewed by participants at the conference, and edited by members of the ABLE Editorial Board. Published abstracts are evaluated and selected by a committee prior to presentation at the conference.

\section{Citing This Article}

Thomas SG, Glover MA, Parthasarathy A, O’Hudson A. 2020. The close-call in microbiology labs - understanding microbes. Article 85 In: McMahon K, editor. Advances in biology laboratory education. Volume 41. Publication of the 41st Conference of the Association for Biology Laboratory Education (ABLE). https://doi.org/10.37590/able.v41.art85

Compilation (C) 2020 by the Association for Biology Laboratory Education, ISBN 1-890444-17-0. All rights reserved. No part of this publication may be reproduced, stored in a retrieval system, or transmitted, in any form or by any means, electronic, mechanical, photocopying, recording, or otherwise, without the prior written permission of the copyright owner.

ABLE strongly encourages individuals to use the exercises in this volume in their teaching program. If this exercise is used solely at one's own institution with no intent for profit, it is excluded from the preceding copyright restriction, unless otherwise noted on the copyright notice of the individual chapter in this volume. Proper credit to this publication must be included in your laboratory outline for each use; a sample citation is given above. 